\title{
Nomadism in Research on Roma Education
}

\section{Solvor Mjøberg Lauritzen}

solvor.m.lauritzen@mf.no

Associate Professor in Education

MF Norwegian School of Theology, Religion and Society

ORCID: https://orcid.org/0000-0003-1357-775X

Dr. Solvor Mjøberg Lauritzen is Associate Professor in Education at MF Norwegian School of Theology, Religion and Society in Oslo, Norway. Her research interests focus on peace education, multicultural education, and critical pedagogy.

\section{Critical}

Romani Studies 


\section{Abstract}

This paper analyzes to what degree and how educational research from a European context explains Roma disadvantage in education by referring to nomadism. Three thematic areas emerged from an analysis of 55 research papers. First, that Roma are closely associated with nomadism in the literature, creating an essentialist discourse. Second, that anti-nomadism contributes to explaining and justifying Roma exclusion. Third, that this impacts how the relationship between Roma and education is uderstood. Nomadism is seen as both incompatible with and in opposition to education, and nomadic learning is seen as a distinct learning style. All in all, the analysis shows that knowledge production on Roma and education has established a discourse where it is legitimate to use nomadism to explain Roma disadvantage in education. This understanding builds on an essentialist view of Romani culture, and it elaborates and sustains key tropes of antigypsyist discourses.

\section{Keywords}

- Roma

- Education

- Nomadism

- Anti-nomadism

- Antigypsyism 


\section{Introduction}

Several years ago I taught a course on national minorities to students pursuing teacher education in Norway. As these students were new to the field, they unwittingly reflected some common stereotypes related to Romani culture and integration. They were shocked to learn how minorities had been persecuted by the state, but when our discussion turned to present-day integration in the classroom, the answer boiled down to how Roma integration basically was impossible because "they travel all the time." Although most of them had never had Roma students in their classes, they assumed that integration was impossible due to nomad traditions. This made me wonder why the nomad aspect of Romani culture was present so strongly in the students' consciousness, and why this trait was viewed as such an insurmountable challenge for the education system.

Established truths about Roma and how these are created and upheld in knowledge production have been challenged by critical scholars in recent years. An important contribution was made in 2015 in the Roma Rights Journal titled "Nothing about Us without Us? Roma Participation in Policy making and Knowledge Production." Starting from the acknowledgement that knowledge production and owning the truth are linked closely with power, the journal challenged the existing knowledge production in Romani Studies (Bogdán, Ryder, and Taba 2015). Established truths such as Roma being a static category, Roma as internal other, and Roma stereotyping were addressed in the journal, which argued that research on Roma has created and upheld such truths to a large extent (Klahn 2015). The authors called for a new direction in Romani Studies where critical perspectives on power and knowledge are to be considered and where Romani scholars take part in the production of scholarship to a larger extent than ever before.

With the story of the students as a starting point, I became interested in exploring how nomadism was used in knowledge production on Roma education. I was interested in finding out whether arguments similar to those of the students also existed in educational research on Roma. Specifically, I was interested in exploring whether Roma disadvantage in education was explained by referring to nomadism so that Roma could be blamed for their own exclusion. This particular question was not new to Romani Studies, where several researchers have criticized the established scholarship for how the relationship between Romani culture and education is understood. For example, Trehan (2009) argues that scholars keep upholding essentialist views on Roma culture where "Romani culture itself is [seen as] inimical to education" (50). Brüggemann (2014) further provides an example of such scholarship where "nomadic lifestyle," among other factors, shoulders the blame for the creation of a particular Romani education system where "reading and writing are supposed to be 'alien concepts' and schools are 'alien institutions' viewed as 'inimical' to Romani culture" (442). Rozzi (2017) further claims that the supposed resistance towards education is by some researchers seen as an essential characteristic of Roma: "The tendency to refuse integration and regular school attendance is interpreted as an 'inborn tendency', somehow related to the nomadic tradition of the Roma population" (20).

This article supplements the above research by providing a broader analysis of how nomadism is used in research on Roma and education. The following research question is asked: To what degree and how does educational research explain Roma disadvantage in education by referring to nomadism? The article 
does not try to explain Roma disadvantage in education but does address exclusively how the relationship between Roma, nomadism, and education has emerged in the research literature. The paper does not consider ways in which nomadism and education are or could be compatible. (For empirical discussions on education and nomadism, see, for example, Griffin 2014; Danaher, Kenny, and Leder 2009.)

\section{Method}

A two-stage process was used to select the material for the analysis that follows in this article. First, 151 peer-reviewed journal articles were identified for review (Lauritzen and Nodeland 2018). These papers were gathered through digital searches combining the terms Gyps $s^{*}$, Roma $^{*}$, or Traveller , with education* or school*. The searches were carried out in four international databases commonly used in educational research: (1) the Education Resources Information Center (ERIC), (2) Sociological abstracts, (3) Web of Science, and (4) PsycINFO. The sample was limited to articles written in English, with a European context, and published in the last 20 years (1997-2016). After the articles had been sampled based on these criteria, those that either were off-topic or did not cover education were removed from the sample. ${ }^{[1]}$ Using this slimmed-down sample as the starting point, the terms nomad ${ }^{*}$, sedentar ${ }^{\star}$, and itiner ${ }^{*}$ were searched for within these articles. Fifty-five of the 151 articles included one or more of these terms and were included in the sample for this paper.

The sample includes papers discussing the following European contexts: Croatia (1), Czech Republic (3), Greece (5), Ireland (5), Italy (4), Portugal (1), Romania (2), Slovakia (1), Slovenia and Serbia (2), Spain (4), and the United Kingdom (25). Another two papers discuss the European level. It is unlikely that this sample is representative of the research field as a whole. The UK is overrepresented by nearly half of the papers, while countries with large Romani populations such as Romania are underrepresented, and large European countries such as Germany and France are unrepresented. This may be because the sample only includes research written in English from peer-reviewed journals, which favors the UK context. Further, references to nomadism might be more prominent in educational research in the UK and Ireland, where semi-nomadism is used more commonly to describe Traveller ethnicity.

The 55 sampled papers were uploaded into ATLAS.ti for coding. Only the paragraphs where the terms nomad $^{*}$, sedentary $^{*}$, or itiner ${ }^{*}$ appeared were included in the coding process. Each paragraph where one of the terms emerged was read through, and as is common in inductively-inspired research, codes were created and applied in the process. At the end of the process, the paragraphs were assigned 12 codes. $^{[2]}$ I allowed for multiple coding, and a single paragraph often was given several codes. The codes formed the basis for writing the analysis presented in this article.

1 This included papers primarily grounded in a different subject area. See Lauritzen and Nodeland (2018) for a more detailed description.

2 These were: anti-education, anti-nomadism, assimilation, comparisons, definitions, discriminatory practices, education, forced sedentarization, identity, nomadic essentialism, nomadic lifestyle, and nomadic practices. 
There are several limitations to this study. The inclusion and exclusion criteria in the data collection influenced what data was analyzed and therefore influenced the findings. Applying other keywords, other geographical contexts, research in other languages, and using other databases would produce different material. Moreover, this study only considered quotes and paragraphs where one of the keywords emerged, meaning that they were taken out of context. This article does not consider the wider context of each article or the context on which the articles were reporting and does not claim to represent some generalizable truth.

\section{Analysis}

As the research question asks "to what degree and how does educational research explain Roma disadvantage in education by referring to nomadism," the main goal is to answer how nomadism, itineracy, and sedentarism emerged in the research literature on Roma and education. The analysis is presented under three main headings: Roma and nomadism; Roma and anti-nomadism; and Roma, nomadism, and education. These three categories emerged from the coding process. The categories are, however, not mutually exclusive but rather overlap and feed into each other. At times, the same papers and even the same quotes are used to illustrate points under all headings. The categories also build on each other to form the main argument.

\subsection{Roma and Nomadism}

In this first section I discuss the association of Roma and nomadism in the literature, and how this association at times creates an essentialist discourse. A range of the papers apply variants of the terms nomadic or sedentary in order to define Roma (Gobbo 2004; Bhopal and Myers 2009; McCaffery 2009; Bhopal 2011a; Bhopal 2011b; Pahic et al. 2011; D’Arcy 2012; Murray 2012; Deuchar and Bhopal 2013). Others do not explicitly state that Roma are nomadic but use different variants of the term "sedentary" to define gadje (e.g., Salinas 2007; O’Hanlon 2010; Murray 2012). For example, although Myers et al. (2010) recognize that "the families included in our study being housed or living on permanent sites" (546), they still write "the sedentary population" (ibid.) when referring to the non-Romani population. Roma therefore are identified as nomads by proxy.

Nomadism is further upheld as an important external identity marker, such as when McCaffery (2009) writes that "the movement from place to place and temporary encampments has possibly more than anything else marked them out from the settled communities" (647). Although the quote seems to give a neutral observation, it is upholding movement as the most important identity marker imposed by outsiders. The latter point is explicitly mentioned by Levinson and Sparkes (2005) who highlight that "[I]mages of the Gypsy nomad, [are] (...) constructed by outsiders" (752). This externally imposed identity marker of nomadism is perhaps most evident in policy documents where it is stated explicitly that Roma must travel in order to be recognized as an ethnic minority, for example, in the Race Relations Act in Britain (Lloyd and McCluskey 2008). Two papers mention a nomadic lifestyle as an internal identity marker (Bhopal 2011b; Levinson 2015), although Levinson (2015) argues that 
other identity markers such as occupational identity is increasingly replacing nomadism among the important identity markers.

In some cases, Roma is so closely associated with nomadism that it creates an essentialist discourse. Essentialism is here understood as the view that there are certain static elements within Romani people or culture that are either unchangeable or seen as necessary for a person or cultural practice to be characterized as Romani. A clear example is where Enguita (2004) resigns to a description of what she labels "an extreme type of Gypsy way of life" when trying to define Roma:

What I do know is that there is, let us say, an extreme type of Gypsy way of life based on a clan, itinerancy, a combination of self-employment and subsistence economy, very different from the Gadge way of life, and that, at some point in between lie most individual Gypsies (...). I am convinced that we shall be better placed to understand the problems of all of them, even those who are closer to the Gadge world, by reference to this extreme type than looking for a mean or modal type that would be difficult to find (202-203).

According to the author, some Roma are more Romani than other, and one of the ingredients of "extreme" Romaniness is leading an itinerant life. What is particularly noteworthy in this rather disturbing quote is that Romaniness is associated exclusively with difference, the opposite of what is seen as gadje. The discussion implies that some Roma are more Romani than others, and that the more a person interacts and associates with "the Gadge way of life", the less Romani a person becomes. Even though the author acknowledges that "most individual Gypsies" are not representative for the "extreme type of Gypsy life", she all the same argues that all Roma people are best understood by reference to "the extreme," including being itinerant.

In other instances nomadism and the role of family in Romani culture is seen in connection. For example: "The extended family is the embodiment of community for Travellers and not a particular geographical location" (Murray 2012, 571).

A few authors further argue that Romani mindsets are essentially nomadic whether they are leading nomadic lives or not (e.g., Lloyd et al. 1999; Levinson and Sparkes 2005; Murray 2012). In one instance this apparent commitment to nomadism is mentioned as a similarity between Roma from the UK and elsewhere in Europe: "They share cultural features with other European Roma/Gypsy groups such as (...) the expression of a strong commitment to a nomadic lifestyle even when living in a house" (Lloyd and McCluskey 2008, 333).

Although the above analysis reveals an essentialist discourse, there are also papers where such views are challenged. A range of papers underline that not all Roma are nomads (Lloyd et al. 1999; Kiddle 2000; Neustupný and Nekvapil 2003; Levinson 2007; Liégeois 2007; McCaffery 2009; Themelis 2009; Bereményi 2011; Murray 2012; Macura-Milovanović et al. 2013; Macura-Milovanović and Peček 2013; Brüggemann 2014; Rosário et al., 2014; Noula et al. 2015). Sedentariness is described as a free choice (Noula et al. 2015) or as a result of assimilation and discrimination (Murray 2012). It is also highlighted in several papers that there are great varieties between different groups who are pursuing a nomadic lifestyle (e.g., Kiddle 
2000; O'Hanlon 2010), and that use of the dichotomy between nomadism and sedentariness disguise heterogeneity among Roma (Levinson and Sparkes 2005). Further, both Derrington (2005) and Zachos (2012) address how static cultural explanations are often promoted at the expense of culture as a dynamic concept, including the view that Roma are helplessly nomadic whether they want it or not.

\subsection{Roma and Anti-nomadism}

In this section I will explore instances where anti-nomadic policies and practices are described and instances where the authors themselves express anti-nomadic attitudes, before concluding the section with analyzing examples where nomadism is blamed for Roma exclusion.

Several papers explicitly refer to anti-nomadism. For example, New and Merry (2010) argue that nomadism has been associated with disease and lawlessness, and several authors argue that such negativity towards nomadism is understood best as a variation of hostility towards Roma (Levinson and Sparkes 2005; New and Merry 2010; Hamilton, Bloomer, and Potter 2012). Others argue that the constructed dichotomy between nomadism and sedentariness is being used to construct otherness (as argued by Doubek et al. 2015) and that nomadism has been interpreted as a racial practice and used as an ethnic marker to distinguish Roma from non-Roma (New and Merry 2010). This ethnic otherness is argued to have been used to strengthen nationalism among non-Roma (Devine et al. 2008; Kitching 2010; Setti 2015).

Setti (2015) gives an example from the Italian context, arguing that "the exonyms 'Nomadic' and 'Gypsies' were used negatively in order to develop a sense of nationalism in the newly created Italian State, denoting Roma and Sinti people as 'ideal inner enemies' to distinguish them from 'true' Italian people" (Setti 2015, 116). An example of such discourse is found in another paper from the Italian context where Trentin et al. (2006) uses nomadism to draw a distinction between "Gypsies" and "our culture": "[G]ypsies have been present on the Italian territory for centuries and, because of their nomadism, have spread everywhere. Our culture, however, is designed for settled societies" (Trentin et al. 2006, 80, emphasis added). Similarly, Enguita (2004) equates nomads with "Gypsies" and draws a stark contrast between sedentary and itinerant lifestyles in Spain, arguing that sedentariness promotes coexistence, assiduous relationships, and "a solid basis to mutual trust relationships" (206). She goes on to argue that "a stable relationship with territory implies a much more careful attitude towards it than itinerancy, and the itinerant's activities almost always become costly externalities for the sedentary dweller" (206). Camouflaged as a neutral description of cultural differences, Enguita ends up arguing indirectly that Roma lives are incompatible with coexistence, assiduous, and mutual trust relationships. A less explicit display of an anti-nomadic attitude is found in Breen (2012), where nomadism is listed as one of several existing prejudices towards Irish Travellers: "disorder, nomadism, laziness, dishonesty, backwardness, [and] dependency" (116). Although the author is attempting here to display already existing prejudice, placing the descriptive term "nomadism" together with other explicitly negative terms gives the impression that "nomadism" is also negative.

A range of papers further discuss how such anti-nomadic attitudes have transformed into anti-nomadic policies and practices, such as laws implemented to restrict the movement of Roma and enforce sedentary lifestyles (Doubek, Levínská, and Bittnerová 2015; Furtuna 2015). These laws range across countries 
and centuries, drawing a picture of a tradition of hostility towards nomadism all across Europe. The oldest law mentioned in the material is from the 1600s in Slovakia (New 2011) and the latest from 2002 in Ireland (Kitching 2010: 218). In several papers sedentarization is argued to be a particular form of assimilation (e.g., Trentin et al. 2006; Salinas 2007; Furtuna 2015) and has therefore become important to resist for some (Levinson and Sparkes 2005). Hamilton, Bloomer, and Potter (2012) argue that such laws were enforced "to get rid of Travellers and other nomadic people around the word" (505). Although Trentin et al. (2006) argue that there has been a development in legislations towards greater acceptance for itinerary lifestyles, McCaffery (2009) argues that the hostility towards those living nomadic or seminomadic lives continues to be so strong that the assimilation into a sedentary lifestyle de facto continues. Legislation aimed at restricting nomadic lifestyles does not always explicitly target Roma. However, due to the strong association of Roma and nomadism, restricting nomadism can be a camouflaged effort to assimilate Roma without having to admit to antigypsyism. New and Merry (2010) refer to a case where, although Roma are not explicitly mentioned in the final version of a particular law, evidence from both the production and implementation of the law show that it is meant to target Roma.

These assimilation laws are by some seen as the reason why most Roma today live sedentary lives (Christianakis 2010; Murray 2012). Others have outlined how Roma have been forced to lead itinerant lives, for example, because Roma were forced to move because they were only allowed to stay for short periods of time in a certain locality (Kelso 2013) or because they were "barred from many localities" (New and Merry 2010, 398). Currently discrimination in housing (O’Hanlon 2010), evictions, and deportations further encourage Roma movement (Kelso 2013).

Roma are closely associated with nomadism, and that policy and research are dominated by antinomadic discourses lays the grounds for blaming Roma for their own exclusion and discrimination. Here, it is irrelevant whether the people described are actually living nomadic lives or not. The main point is that reference to a nomadic lifestyle is used to justify and explain exclusion. Bowen (2004) writes "their unpredictable nomadic lifestyle" (57), which indicates that it was the way of living that was the problem rather than the institutions. Similarly, Enguita (2004) argues that, "Gypsies remained in a great measure outside because of their itinerant way of life" (212), and O'Hanlon (2010) states that, "Traveller and Gypsy children, because they live a nomadic existence and live in mobile homes, are often stereotyped and discriminated against" (245). Chronaki (2005) stirs identity into the mix, adding that holding a cultural identity also leads to discrimination: "The Gypsy community in Europe is perhaps the most stigmatised and marginalized due to its semi-nomadic lifestyle and its strong cultural identity that is visible physically" (62). Because the authors write "because of" or "due to" and label itineracy as unpredictable, the Roma lifestyle is indirectly pointed to as the problem. Even if the authors might be of the opinion that society at large should adjust to this difference, they are using the difference to explain exclusion rather than using intolerance in society at large as a starting point.

\subsection{Roma, Nomadism, and Education}

This paper has presented the strong association of Roma and (anti-)nomadism in the research sample. Below I consider how these connections intersect with how Roma education is discussed in the 
research literature. First, I analyze how nomadism is understood as incompatible with education, and the perception that nomadism is in opposition to education. I then move on to explore the discourse promoting nomadic and Roma learning as a particular learning style.

A range of papers considered nomadism and education to be more or less incompatible. One strand in the material portrayed nomadism as an obstacle for education. Common to these quotes is that the responsibility for attendance and achievement is placed on the group rather than on the school system (Bowen 2004; McCaffery 2009; Myers et al. 2010; Kiprianos et al. 2012; Levinson 2015). For example: "their [Roma] alternative ways of economic activity, thinking and living often expressed in a nomadic way of life, make their incorporation into many mainstream institutional processes, such as schooling, difficult" (Kiprianos et al. 2012, 693). In one paper, nomadism is, together with Roma identity, given the blame for non-attendance in school: “Those Gypsy Traveller families who still travel and take pride in their identity are more likely to keep their children away from secondary schools" (Kiddle 2000, 273, emphasis added). A second strand highlighted that the reason why nomadism is an obstacle for education is because schools are not adjusting to their pupils (Bhopal 2004; Levinson 2007). For example: "Schools work on the basis of sedentary lifestyles and it is the norms of such lifestyle that Gypsy and Traveller pupils must conform to" (Bhopal 2011a, 480). Although nomadism still is seen as an obstacle for education in this quote, it differs from the above in clearly placing both the cause and the responsibility to solve it with the school. A third strand in the material considers nomadism as an obstacle for education in relation to discrimination in housing and evictions, highlighting that parents are forced to take their children out of schools when they are evicted or discriminated against when trying to access sites or housing (Themelis 2009). For example: "This [moving to avoid evictions] results in irregular school attendance and has a detrimental effect on the education of many Gypsy Travellers" (Bhopal 2004, 49).

In some papers it was not the nomadism per se but attitudes held by "nomads" and "nomadic cultures" that was seen as the problem. Some authors claim that education is not seen as relevant among people living a nomadic lifestyle (Levinson and Sparkes 2006; Levinson 2007), whereas others argue that Roma are in opposition to education: "Gypsies and Traveller communities expressed a disdain for formal education which many rejected" (McCaffery 2009, 644); "there was neither the will nor the means to assure universal schooling, because they themselves had no great desire to appear in the classrooms" (Enguita 2004, 212); and " $[t]$ here is a core of underlying attitudes/values, forged over many generations, that would militate against the acquisition of formal literacy whatever the attendance rates of those concerned" (Levinson 2007). Levinson (2007) continues by citing a 30-year-old source to back the argument that Roma oppose literacy:

Even among those who have settled, a deep suspicion of literacy can persist, as reflected, for instance, in the belief that 'when you learn to read and write, you lose your memory' (Kiddle, 1999: 65) and that literacy is 'inimical to the development of memory and intelligence - a skill for servants and secretaries, not for businessmen like themselves' (Liegeois, 1987: 60) (12).

In trying to explain why Roma are resisting education, some authors argue that the cultural differences are too vast, that there is "a mismatch between Traveller and school culture, with disregard for nomadic traditions viewed as discouraging Travellers from actively engaging with school” (Darmody et al. 2008), or that "it is very difficult to motivate him or her [the gypsy child] to learn and assimilate ideas and values 
that are very different from his or her own experience and cultural background" (Trentin et al. 2006, 82). Others argue that Roma resist education because it is perceived as a threat: "For groups whose identities are based on some form of nomadic existence, a school system that would appear to prepare children for an essentially sedentary existence, centered around workplace, is likely to be perceived as a threat" (Levinson and Hooley 2014, 384).

Several papers explicitly address anti-nomadism in the education system, expressed both as assimilation and exclusion. Some argue that education has been used in the past (Miskovic 2009; Themelis 2009) and more recently (Harry et al. 2008; Gobbo 2011) to assimilate Roma into a sedentary lifestyle, and that nonattendance therefore could be seen as a way of resisting assimilation (Levinson and Sparkes 2005). Others address schools excluding pupils from nomadic cultures historically (Bowen 2004), and in the present (Bhopal 2004; Hamilton, Bloomer, and Potter, 2012). Hostile attitudes towards Roma pupils and families are also addressed in several papers. Hately-Broad (2004) argues that whereas "distrust and suspicion" are directed towards all Roma from gadje, "this distrust is magnified in relation to a nomadic population" (273). Bhopal (2011b) further lifts the voices of parents to the foreground, who argue that teachers do not like it when they travel with their children to attend funerals or horse fairs. Labelling this type of traveling a "nomadic lifestyle," the paper claims that this identity trait is more important for many parents than sending their children to school. Derrington (2007) argues that rather than actual travelling, it is precisely these anti-nomadic sentiments that keep children out of school. In explaining non-attendance, Kiddle (2000) emphasizes that parents who have been discriminated against in schools want to protect their children from similar treatment. After making this point, however, the authors move directly to a discussion of nomadism, arguing that "nomadism itself would mean an interrupted schooling and access could not be guaranteed” (Kiddle 2000, 266). Similarly, Myers et al. (2010) highlight that parents might keep their children out of school to protect them from racism and cultural erosion. This "cultural erosion" is elsewhere in the article explained as "culture of the sedentary population," which in turn cements Roma in a nomadic lifestyle. This practice, of seeing all Roma as nomads, could according to Gobbo (2011) be seen as a particular form of discrimination: "[T]he attribution of the nomadic identity that is not theirs, conveys to Roma pupils what non-Roma teachers, for instance, believe about them; namely, that the teacher identifies each of them: [A]s a 'nomad', not as a pupil" (18).

Some papers uphold nomadic learning as a distinct learning style. Coming from the starting point that " $\mathrm{t}]$ here are fundamental differences between Gypsy Traveller lifestyles and those of the 'settled' population, both in terms of social and ethnic status and a nomadic way of life" (59), Bhopal (2004) argues that, "[s]chools need to offer a 'hands on' approach in the classroom with an emphasis on issues and subjects that are relevant to the needs of everyday life. In the case of Gypsy Travellers these need to reflect and value the differences of nomadic lifestyle and culture" (61). Similarly, Trentin et al. (2006) describe how schools have to adjust their teaching for Roma children: "The enrolment of nomadic students (...) has required teachers to invent alternative teaching approaches to direct education (...) or demonstrating typical gypsy work at the school" (82). Others argue that Roma children, to a higher degree than gadje pupils, value informal education (e.g., Deuchar and Bhopal 2013), and that this can lead to difficulties in adjusting:

Designed as they are for mainstream groups following an essentially sedentary lifestyle, educational systems simply overlook the difficulties of adaptation for children from a 
nomadic background. For the youngsters from each community, the dichotomy between formal and informal learning systems results in difficult choices, which have an impact not only on aspirations, future work and lifestyles, but also upon wider identities (Levinson and Hooley 2014, 384-385).

Bhopal (2011a) argues that schools are "designed to fit the needs of the majority population rather than the minority (such as nomadic groups)" (472) and highlights special orientation in particular: "The spatial element of the school and its structured environment imposes restrictions on Gypsy and Traveller children's behaviour, which they may not be used to" (ibid.), since "[f] or many nomadic groups learning takes place by the family and extended kinship network" (480). That Roma children hold fundamentally different orientations towards space is also argued by Levinson and Sparkes (2005). They argue that, "Gypsy children inhabit spatial environments radically dissimilar to those of mainstream children" (751), and that it is important to consider how this impacts on school adaptation. Integrating all the above mentioned claims on differences between Roma and non-Roma learning, Trentin et al. (2006) equate the "Gypsy child" with a "nomadic child" and arrives at the conclusion that the different education systems of the two groups are so vast that school can be unbearable for Roma:

Anthropologically there is a notable difference between the educational systems of nomadic and non-nomadic groups. The schools of the gagé (non-gypsies) are organized according to a rigid discipline of time and space, division of classes by age, and a primarily verbal and artificial way of teaching, with education lasting until or beyond adolescence. The gypsy child, on the other hand, learns by listening and through concrete action that takes place within the clan, passing precociously from infancy into adulthood. Gypsy children are fundamentally free. They are used to moving around in open spaces with few rules governing them. As a consequence, being confined for many hours in a structured closed environment, i.e. the school, can be unbearable for them (81).

In some instances, the belief that Roma children's learning styles are fundamentally different from those of gadje children, and that they require a different curriculum from the majority children, has led to segregated education initiatives, such as the "nomads' workshops" described in Gobbo (2011): "The separate, excluding arrangement paradoxically allows Roma pupils to maintain their ethnic identity at the price of their identity as pupils, while it frustrates the teachers' efforts to provide learning to their nomadic pupils" (18).

\section{Discussion}

The above analysis revealed three main discourses related to Roma and nomadism in educational research: (1) Roma are closely associated with nomadism, (2) nomadism is mainly understood in negative terms so that it can be understood as anti-nomadism, and (3) this lays the ground for understanding Roma disadvantage in education based on apparent nomadism, thus making Roma too different for the regular education system. 
In the first section of the analysis, the association between Roma and nomadism was explored. References made to nomadism when seeking to define Roma were analyzed, as well as the reference to nomadism as both an internal and external identity marker. Finally, I analyzed essentialist understandings of Roma and nomadism. For example, one paper promoted "[G]ypsiness" as something that can be measured on a scale, so that one can arrive at a description of an extreme "Gypsy." Another view visible in several papers was that although this apparently extreme "Gypsy" life may be abandoned by a Romani individual, Romani people's mindsets will remain fundamentally different from those of the gadje majority, particularly in relation to nomadic culture which is claimed to influence Romani people's way of thinking and acting. These understandings resemble what Selling (2015) describes as "the fictional character of the conceptual Gypsy, which in antiziganist discourse is projected onto Roma and other persons" (120). The abovementioned ideas of "[G]ypsiness," including innate nomadism, constitute characteristics of this "conceptual Gypsy." When these are linked with identity, one easily arrives at what McGarry (2017) labels "an ethnicized identity," defined as a process of dissimilation leading to ethnogenesis, "where the group is understood by supposedly essential characteristics such as nomadism" (20). The resilience of this antigypsyist discourse is illustrated in the analysis here: when the essentialist claim that all Romani persons are nomads is confronted with empirical evidence that in fact most are sedentary, the image of "the conceptual Gypsy" strikes back by claiming that despite Roma being sedentary, they have nomadic mindsets. As such, the first part of the analysis reveals a discourse which inseparably connects Roma with nomadism.

When the association between Roma and nomadism was established, the second section of the analysis moved on to explore Roma and anti-nomadism. After having outlined how the research papers describe anti-nomadic policies and practices historically and in more recent times, I moved on to explore expressions of anti-nomadic sentiments in the papers, where it seems that anti-Roma and anti-nomadic sentiments feed into and strengthen each other. This connection has been pointed out by, for example, Donahue, McVeigh, and Ward (2003) who argue that although racism and anti-nomadism are distinct phenomena, "this discrimination manifests usually in combination - both phenomena are often experienced simultaneously" (39). McVeigh (1997) argues that anti-nomadism stems from sedentarism, which is defined as "that system of ideas and practices which serves to normalize and reproduce sedentary modes of existence and pathologies and repress nomadic modes of existence" (9). The notion of sedentarism, McVeigh (1997) argues, include both incitement of direct hate-speech and acts against nomadic groups, and the subtler sedentary normativity embedded in "ideas, actions and structures which construct being sedentary as the only possible mode of existence within contemporary society" (9). Anti-nomadism therefore does not only affect Roma but is rather a "cultural universal" (Donahue, McVeigh, and Ward 2003, 39). Anti-nomadism stretches back in time, and as with other versions of racism, a nomadic lifestyle was previously given genetic explanations (ibid. 40). Anti-nomadism is also a worldwide phenomenon, where a sedentary normativity causes tension with nomadic communities all around the world (ibid.). Ellwood (in Donahue, McVeigh, and Ward 2003, 39) argues that nomadism is seen as unmodern, and that nomadic peoples therefore should be settled both for their own good and for the good of the nation. The reasoning leading to these conclusions, she argues, is often benevolent and patronizing (39). This universal anti-nomadism intersects and escalate with antigypsyism, which according to Knudsen (2016) "has to be understood as an instrument of stigmatisation, whose intent is not to observe and understand the circumstances of the 'other' side, but to find elements of identification that legitimate separation and other discriminative actions against those 'others'” Nomadism seems to have acted 
as a particularly important element for such legitimatization of discrimination historically. Wippermann (2015) argues that social antigypsyism is grounded in this very understanding that Roma have chosen freely "to be eternal wanderers" (5), and McGarry (2017) adds that the idea of nomadism has made it possible to see Roma as not really belonging to the states where they hold citizenship: "Roma are seen as a problem community that does not 'fit' the projection of the nation" (8). As the sedentary-normative mindset is a cultural universal, nomadism is associated strongly with Roma to the extent that it is understood as an essential part of Romani identity and culture, and nomadism is established as playing a particular role in antigypsyist ideology, ground is laid for using nomadism to blame Roma for their own exclusion. The analysis in this article showed that this is the case also in educational research. The field is therefore contributing to an antigypsyist discourse where anti-nomadism is used to legitimize Roma exclusion.

The third section of the analysis addressed the intersection between Roma, education, and anti-nomadism in the research literature. I started by analyzing how nomadism is seen as both incompatible with and in opposition to education. Roma disadvantage in education could be analyzed with reference to dimensions applied in other comparable contexts such as poverty and rurality (UNESCO 2015), pressing issues such as segregation in areas such as housing and schooling (e.g., Rostas 2012; Picker 2017), or effects of hate violence such as forced evictions (Björgo and Witte 1993; Stewart 2012). Although these dimensions are also present in research on Roma and education, the analysis in this paper also revealed that nomadism is seen as both incompatible with and in opposition to education. Since Roma already have been tied to nomadism, and nomadism is understood as fundamentally negative, it comes as no surprise that discourses exist where the problem of integration is placed squarely upon Roma rather than the education system. It is a vicious circle that is difficult to escape. As End (2015) puts is: "these patterns of prejudice have existed, and they take recourse to whatever empirical facts seem useful to justify such biases: for example, if Romani children don't attend school, they are seen as primitive and hostile to education. If they attend school, they are viewed as a threat to the education of non-Romani children" (103). The analysis also revealed a tendency to understand nomadic learning as a distinct learning style, which resembles the discussions on essentialism and nomadism as a reason for exclusion. It is a similar discourse formation that is found here. Even when Roma are not travelling, they are perceived to have nomadic mindsets. According to this way of thinking, Roma require a different pedagogy in order to learn. Their insurmountable difference is seen as the reason for their disadvantage in education. An alternative approach to the issue could be to focus on the antinomadism rather than the apparent nomadism when seeking to explain Roma disadvantage in education.

The analysis revealed a discourse in educational research where Roma are associated strongly with nomadism, nomadism is almost solely understood in negative term, and this apparent nomadism is used to "blame the victim" so that Roma exclusion can be explained with reference to nomadism. To contribute to such an argument was probably not the intention for many of the researchers. It is worth quoting Hancock's essay (2010) on fake Romani culture: “To be fair, not all fake Romani culture has been faked deliberately. More often it is simply the result of misguided or misinformed hypotheses finding their way into the conversational account, and being repeated by subsequent writers unchecked" (177). Simply put, references to nomadism have become such an established part of the discourse in educational research that it has become an unquestioned truth which is being reproduced. This might lead to what Kwiek (2009) labels unintentional exclusion. In their attempt to understand Romani minds and culture, scholars unintentionally sustain and elaborate exclusionary discourses with the help of antigypsyist projections 
of Romani people as eternal wanderers. This is an example of how research and established knowledge production have upheld stereotypes and the understanding of Roma as a static category.

\section{Conclusion}

This paper has explored to what degree and how educational research explains Roma disadvantage in education by referring to nomadism. Out of 151 systematically sampled research papers, 55 included the terms nomadic, itinerant, or sedentary. The analysis that was carried out suggests that the idea of nomadism has played an important role in the knowledge production on Roma and education. On the most basic level, many researchers use the terms nomadic or itinerant to define Roma, some to the extent that it resembled an essentialist view of Romani culture, creating and establishing a strong association between Roma and nomadism. Furthermore, nomadism is largely understood as deviant and a challenge for society. Many of the research papers analyzed raised this issue by referring to anti-nomadic policies and practices. Other research papers expressed anti-nomadic attitudes, such as using nomadism to blame Roma for their own exclusion. The analysis further considered how nomadism is used to explain Roma disadvantage in education, either because nomadism is seen as incompatible with or in opposition to education, or because nomadism is seen as a distinct learning style. Based on this analysis, the paper has argued that educational research on Roma resembles antigypsyist discourses where essentialism, antinomadism, and sedentarism have played important roles.

\section{References}

Bereményi, Bálint-Ábel. 2011. "Intercultural Policies and the Contradictory Views of Teachers: The Roma in Catalonian Schools." Intercultural Education 22 (5): 355-369. https://doi.org/10.1080/14675986.2011.643134.

Bhopal, Kalwant. 2004. “Gypsy Travellers and Education: Changing Needs and Changing Perceptions.” British Journal of Educational Studies 52 (1): 47-64. https://doi.org/10.1111/j.1467-8527.2004.00254.x.

Bhopal, Kalwant. 2011a. “This Is a School, It's Not a Site': Teachers' Attitudes towards Gypsy and Traveller Pupils in Schools in England, UK.” British Educational Research Journal 37 (3): 465-483. https://doi.org/10.1080/01411921003786561.

. 2011b. "What about Us?' Gypsies, Travellers and 'White Racism' in Secondary Schools in England." International Studies in Sociology of Education 21 (4): 315-329. https://doi.org/1080/09620214.2011.640520.

Bhopal, Kalwant, and Martin Myers. 2009. "Gypsy, Roma and Traveller Pupils in Schools in the UK: Inclusion and 'Good Practice." International Journal of Inclusive Education 13 (3): 299-314. https://doi.org/10.1080/13603110701748403.

Björgo, Tore, and Rob Witte, eds. 1993. Racist Violence in Europe. London: Palgrave Macmillan.

Bogdán, Mária, Andrew Ryder, and Marius Taba. 2015. “The Roma Spring: Knowledge Production and the Search for a New Humanity." Roma Rights Journal of European Roma Rights Centre 2: 33-37.

Bowen, Paul. 2004. "The Schooling of Gypsy Children in Surrey 1906-1933." Journal of Educational Administration and History 36 (1): 57-67. https://doi.org/10.1080/0022062042000177674. 
Breen, Majella. 2012. "An 'Other' Perspective: Emancipation in Alterity?” The Irish Journal of Adult and Community Education: 115-124.

Brüggemann, Christian. 2014. "Romani Culture and Academic Success: Arguments against the Belief in a Contradiction." Intercultural Education 25 (6): 439-452. https://doi.org/10.1080/14675986.2014.990229.

Christianakis, Mary. 2010. "Lessons for Life: Roma Children, Communal Practices, and the Global Marketplace." Perspectives on Urban Education (Fall): 11-18.

Chronaki, Anna. 2005. "Learning about 'Learning Identities' in the School Arithmetic Practice: The Experience of Two Young Minority Gypsy Girls in the Greek Context of Education." European Journal of Psychology of Education XX (1): 61-74.

D’Arcy, Kate. 2012. "Learning and Digital Inclusion: The ELAMP Project." Research in Learning Technology 20: 417-429. https://doi.org/10.3402/rlt.v20i0.18603.

Danaher, Alan, Máirín Kenny, and Judith Remy Leder. 2009. Traveller, Nomadic and Migrant Education. London: Routledge.

Darmody, Merike, Emer Smyth, and Selina McCoy. 2008. "Acting up or Opting out? Truancy in Irish Secondary Schools." Educational Review 60 (4): 359-373. https://doi.org/10.1080/00131910802393399.

Derrington, Chris. 2005. "Perceptions of Behaviour and Patterns of Exclusion: Gypsy Traveller Students in English Secondary Schools. Journal of Research in Special Educational Needs 5 (2): 55-61. https://doi.org/10.1111/J.1471-3802.2005.0042.x.

_ 2007. "Fight, Flight and Playing White: An Examination of Coping Strategies Adopted by Gypsy Traveller Adolescents in English Secondary Schools." International Journal of Educational Research 46: 357-367. https://doi.org/10.1016/j.ijer.2007.06.001.

Deuchar, Ross, and Kalwant Bhopal. 2013. “'We're Still Human Beings, We're Not Aliens': Promoting the Citizenship Rights and Cultural Diversity of Traveller Children in Schools: Scottish and English Perspectives." British Educational Research Journal 39 (4): 733-750. https://doi.org/10.1080/01411926.2012.67925.

Devine, Dympna, Máirín Kenny, and Eileen Macneela. 2008. "Naming the 'Other’: Children’s Construction and Experience of Racism in Irish Primary Schools." Race Ethnicity and Education 11 (4): 369-385. https://doi.org/10.1080/13613320802478879.

Donahue, Mark, Robbie McVeigh, and Maureen Ward. 2003. Misli, Crush, Misli: Irish Travellers and Nomadism. Dublin: Irish Traveller Movement and Traveller Movement Northern Ireland.

Doubek, David, Marketa Levínská, and Dana Bittnerová. 2015. "Roma As the Others." Intercultural Education 26 (2): 131-152. https://doi.org/10.1080/14675986.2015.1027084.

End, Markus. 2015. “Antigypsyism: What's Happening in a Word?” In Antiziganism. What's in a Word? edited by Jan Selling, Markus End, Hristo Kyuchukov, Pia Laskar and Bill Templer. Newcastle, UK: Cambridge Scholars Publishing.

Enguita, Mariano F. 2004. “School and Ethnicity: The Case of Gypsies.” Pedagogy, Culture \& Society 12 (2): 201-216. https://doi.org/10.1080/14681360400200196.

Furtuna, Adrian-Nicolae. 2015. "Essay on Personal Field Experiences from an Intercultural Approach." Intercultural Education 26 (2): 106-113. https://doi.org/10.1080/14675986.2015.1023010.

Gobbo, Francesca. 2004. "Cultural Intersections: The Life Story of a Roma Cultural Mediator." European Educational Research Journal 3: 626-641. https://doi.org/10.2304/eerj.2004.3.3.6. 
2011. "Racism, 'Race' and Ethnographic Research in Multicultural Italy." Ethnography and Education 6 (1): 9-27. https://doi.org/10.1080/17457823.2011.553077.

Griffin, Rosarii. 2014. Education in Indigenous, Nomadic and Travelling Communities. London: Bloomsbury.

Hamilton, Jennifer, Fiona Bloomer, and Michael Potter. 2012. “The Adequacy of Traveller Education in Northern Ireland. Race Ethnicity and Education 15 (4): 501-524. https://doi.org/10.1080/13613324.2011.645574.

Hancock, Ian. 2010. “The Concocters: Creating Fake Romani Culture.” In Danger! Educated Gypsy. Selected Essays, edited by Dileep Karanth. Hatfield, UK: University of Hertfordshire Press.

Harry, Elizabeth, Pilar Arnaiz, Janette Klingner, and Keith Sturges. 2008. "Schooling and the Construction of Identity among Minority Students in Spain and the United States." The Journal of Special Education 42 (1): 15-25.

Hately-Broad, Barbara. 2004. "Problems and Good Practice in Post-compulsory Educational Provision for Travellers: The Wakefield Kushti project.” Intercultural Education 15 (3): 267-281. https://doi.org/10.1080/1467598042000262563.

Kelso, Michelle. 2013. “'And Roma Were Victims, Too.' The Romani Genocide and Holocaust Education in Romania." Intercultural Education 24 (1-2): 61-78. https://doi.org/10.1080/14675986.2013.768060.

Kiddle, Cathy. 2000. "Partnerships Depend on Power-sharing: An Exploration of the Relationships between Fairground and Gypsy Traveller Parents and Their Children's Teachers in England." International Journal of Educational Research 33: 265-274.

Kiprianos, Pandelis, Ivi Daskalaki, and Georgios B. Stamelos. 2012. "Culture and the School: The Degree of Educational Integration of Roma and Gypsies in the Peloponnese Region of Greece." International Review of Education 58: 675-699. https://doi.org/10.1007/s11159-012-9326-0.

Kitching, Karl. 2010. "An Excavation of the Racialised Politics of Viability Underpinning Education Policy in Ireland." Irish Educational Studies 29 (3): 213-229. https://doi.org/10.1080/03323315.2010.498278.

Klahn, Marett Katalin. 2015. "Knowing Differently: On Thinking and Doing 'Roma." Roma Rights Journal of European Roma Rights Centre 2: 63-69.

Knudsen, Marko D. 2016. “Antiziganism definition - Antiziganism Vs. Antigypsyism.” Europäisches Zentrum für Antiziganismusforschung.

Kwiek, Gregor. 2009. “Unintentional Exclusion.” Romani E Journal 1: 5-15.

Lauritzen, Solvor Mjøberg, and Tuva Nodeland. 2018. “'What is the Problem Represented to Be?' Two Decades of Research on Roma and Education in Europe." Educational Research Review 24: 148-169. https://doi. org/10.1016/j.edurev.2018.04.002.

Levinson, Martin P. 2007. "Literacy in English Gypsy Communities: Cultural Capital Manifested as Negative Assets." American Educational Research Journal 44 (1): 5-39. https://doi.org/10.3102/0002831206298174.

—. 2015. "'What's the Plan?' 'What Plan?' Changing Aspirations among Gypsy Youngsters, and Implications for Future Cultural Identities and Group Membership." British Journal of Sociology of Education 36 (8): 11491169. https://doi.org/10.1080/01425692.2014.897217.

Levinson, Martin, and Neil Hooley. 2014. "Supporting the Learning of Nomadic Communities across Transnational Contexts: Exploring Parallels in the Education of UK Roma Gypsies and Indigenous Australians." Research Papers in Education 29 (4): 373-389. https://doi.org/10.1080/02671522.2013.772223.

Levinson, Martin. P., and Andrew C. Sparkes. 2005. "Gypsy Children, Space, and the School Environment." International Journal of Qualitative Studies in Education 18 (6): 751-722.

https://doi.org/10.1080/09518390500298212. 
2006. “Conflicting Value Systems: Gypsy Females and the Home-school Interface." Research Papers in Education 21 (1): 79-97. https://doi.org/10.1080/02671520500335907.

Liégeois, Jean-Pierre. 2007. “Roma Education and Public Policy: A European Perspective.” European Education 39 (1): 11-31. https://doi.org/10.2753/EUE1056-4934390101.

Lloyd, Gwynedd, and Gillean McCluskey. 2008. "Education and Gypsies/Travellers: 'Contradictions and Significant Silences.” International Journal of Inclusive Education 12 (4): 331-345. https://doi.org/10.1080/13603110601183065.

Lloyd, Gwynedd, Joan Stead, Elizabeth Jordan, and Claire Norris. 1999. “Teachers and Gypsy Travellers.” Scottish Educational Review 31: 48-65.

Macura-Milovanović, Sunčica, Milanka Munda, and Mojca Peček. 2013. "Roma Pupils’ Identification with School in Slovenia and Serbia: Case Studies." Educational Studies 39 (5): 483-502.

https://doi.org/10.1080/03055698.2013.801768.

Macura-Milovanović, Sunčica, and Mojca Peček. 2013. “Attitudes of Serbian and Slovenian Student Teachers towards Causes of Learning Underachievement among Roma Pupils.” International Journal of Inclusive Education 17 (6): 629-645. https://doi.org/10.1080/13603116.2012.703247.

McCaffery, Juliet. 2009. "Gypsies and Travellers: Literacy, Discourse and Communicative Practices." Compare: A Journal of Comparative and International Education 39 (5): 643-657. https://doi.org/10.1080/03057920903125685.

. 2014. "Identities, Roles and Iterative Processes: Methodological Reflections from Research on Literacy among Gypsies and Travellers.” Research in Comparative and International Education 9: 375-386. https://doi. org/10.2304/rcie.2014.9.4.375.

McGarry, Adam. 2017. Romaphobia. The Last Acceptable Form of Racism. London: Zed Books.

McVeigh, Robbie. 1997. “Theorising Sedentarisation: The Roots of Anti-nomadism.” In Gypsy Politics and Traveller Identity, edited by Thomas Acton, 7-25. Hatfield: University of Hertfordshire Press.

Miskovic, Maja. 2009. "Roma Education in Europe: In Support of the Discourse of Race. Pedagogy, Culture \& Society 17 (2): 201-220. https://doi.org/10.1080/14681360902934442.

Murray, Colette. 2012. "A Minority within a Minority? Social Justice for Traveller and Roma Children in ECEC." European Journal of Education 47 (4): 469-583.

Myers, Martin, Derek McGhee, and Kalwant Bhopal. 2010. “At the Crossroads: Gypsy and Traveller Parents' Perceptions of Education, Protection and Social Change. Race Ethnicity and Education 13 (4): 533-548. https://doi.org/10.1080/13613324.2010.492138.

Neustupný, Jirí.V. and Jirí Nekvapil. 2003. “Language Management in the Czech Republic.” Current Issues in Language Planning 4 (3-4): 181-366. https://doi.org/10.1080/14664200308668057.

New, William. 2011. "Stigma and Roma Education Policy Reform in Slovakia." European Education 43 (4): $45-61$. https://doi.org/10.2753/EUE1056-4934430403.

New, William S. and Michael S. Merry. 2010. "Solving the "Gypsy Problem": D.H. and Others v. the Czech Republic." Comparative Education Review 54 (3): 393-414.

Noula, Ioanna, Steven Cowan, and Christos Govaris. 2015. "Democratic Governance for Inclusion: A Case Study of a Greek Primary School Welcoming Roma Pupils.” British Journal of Educational Studies 63 (1): 47-66. https://doi.org/10.1080/00071005.2014.984654. 
O'Hanlon, Christine. 2010. "Whose Education? The Inclusion of Gypsy/Travellers: Continuing Culture and Tradition through the Right to Choose Educational Opportunities to Support Their Social and Economic Mobility." Compare: A Journal of Comparative and International Education 40 (2): 239-254. https://doi. org/10.1080/03057920903546104.

Pahic, Tea, Vlasta Vizek Vidovic, and Renata Miljevic-Ridicki. 2011. "Involvement of Roma Parents in Children's Education in Croatia: A Comparative Study." Journal of Research in International Education 10 (3): 275-292. https://doi.org/10.1177/1475240911422484.

Picker, Giovanni. 2017. Racial Cities: Governance and the Segregation of Romani People in Urban Europe. Oxford: Routledge.

Rosário, Pedro, José Carlos Núñez, Raquel Azevedo, Jennifer Cunha, Armanda Pereira, and Rosa Mourão. 2014. "Understanding Gypsy Children’s Conceptions of Learning: A Phenomenographic Study." School Psychology International 35 (2): 152-166. https://doi.org/10.1177/0143034312469304.

Rostas, Iulius, ed. 2012. Ten Years After: A History of Roma School Desegregation in Central and Eastern Europe. Budapest: Central European University Press.

Rozzi, Elena. 2017. "Roma Children and Educational Exclusion in Italy." In Realizing Roma Rights, edited by Jacqueline Bhabha, J., Andrzej Mirga and Margareta Matache, 17-38. Philadelphia, PA.: Pennsylvania University Press.

Salinas, Jesus. 2007. "Reflections on Educational Policies for Spanish Gypsies." European Education 39 (1): 32-49. https://doi.org/10.2753/EUE1056-4934390102.

Selling, Jan. 2015. “The Conceptual Gypsy: Reconsidering the Swedish Case and the General.” In Antiziganism. What's in a Word? edited by Jan Selling, Markus End, Hristo Kyuchukov, Pia Laskar and Bill Templer. Newcastle, UK: Cambridge Scholars Publishing.

Setti, Federica. 2015. "The Implications of 'Naming' on Roma and Sinti Right to Education and Social Inclusion: An Ethnography of Education among a Sinti Family Network. Intercultural Education 26 (2): 114-130. https://doi.or g/10.1080/14675986.2015.1023011.

Stewart, Michael, ed. 2012. The Gypsy 'Menace'. Populism and the New Anti-Gypsy Politics. London: Hurst \& Company.

Themelis, Spyros. 2009. "Questioning Inclusion: The Education of Roma/Traveller Students and Young People in Europe and England - A Critical Examination." Research in Comparative and International Education 4 (4): 262-275. https://doi.org/10.2304/rcie.2009.4.3.262.

Trehan, Nidhi. 2009. Human Rights Entrepreneurship in Post-socialist Hungary: From the 'Gypsy Problem' to 'Romani Rights'. PhD Diss., London School of Economics and Political Science.

Trentin, Rosanna, Maria G. Monaci, Filomena De Lumè, and Ombretta Zanon. 2006. "Scholastic Integration of Gypsies in Italy." School Psychology International 27 (1): 79-103. https://doi.org/10.1177/0143034306062816.

UNESCO. 2015. “Education for All 2000-2015: Achievements and Challenges.” Paris: UNESCO.

Wippermann, Wolfgang. 2015. “The Longue Durée of Antiziganism as Mentality and Ideology. In Antiziganism. What's in a Word? edited by Jan Selling, Markus End, Hristo Kyuchukov, Pia Laskar and Bill Templer. Newcastle, UK: Cambridge Scholars Publishing.

Zachos, Dimitris. 2012. "Institutional Racism? Roma Children, Local Community and School Practices. Journal for Critical Education Policy Studies 10 (1): 53-66. 